\title{
An Evaluation System for Enterprise Culture Management Based on Entropy and Fuzzy Evaluation Method
}

\author{
Jiafu Su \\ Chongqing Key Laboratory of Electronic Commerce \& \\ Supply Chain System \\ Chongqing Technology and Business University \\ Chongqing, China \\ jiafu.su@hotmail.com
}

\author{
Hui Huang \\ Chongqing Key Laboratory of Electronic Commerce \& \\ Supply Chain System \\ Chongqing Technology and Business University \\ Chongqing, China
}

\begin{abstract}
In order to resolve the problem that the evaluation of enterprise culture management was hard to be accurately evaluated, an evaluation system and approach for enterprise culture management was proposed. Firstly, in view of whole life cycle of enterprise culture development, the basic process of the enterprise culture management was defined based on PDCA theory, and an enterprise culture management evaluation index system was built. Then, the entropy was used to revise the score of expert's experience, and to determine the more objective and accurate index weight. At the same time, the fuzzy comprehensive evaluation method was implied to carry out the evaluation. Finally, the feasibility and effectiveness were verified by the evaluation of enterprise culture management of the county power supply company.
\end{abstract}

Keywords-Enterprise culture management; PDCA; Evaluation index system; Entropy; Fuzzy comprehensive evaluation.

\section{INTRODUCTION}

The excellent enterprise culture is an important part of the core competence of modern enterprise, which is the inexhaustible driving force for enterprises to realize sustainable development[1]. In enterprise culture management, the evaluation of enterprise culture management is a new thing, and most of the existing researches are limited to the qualitative evaluation[2]. However, in order to obtain a clear and accurate description of the level, hierarchy and function of enterprise culture management, quantitative evaluation of enterprise culture management is needed. As a pioneer, Hofstede et.al adopt questionnaire survey and Delphi method to evaluate enterprise culture[3]. According to the characteristics of the Chinese enterprises, Deshpande and Farley, and Tian et.al introduced and improved the western corporate culture measurement tools to evaluate Chinese enterprises' corporate culture from the view of the basic properties and characteristic of enterprise culture[4,5]. Fu and Xiong et.al comprehensively evaluates the cultural management of enterprises from four levels: spiritual, institutional, behavioral and physical[2,6]. Wang et.al used the repertory grid and the fuzzy Borda method to evaluate the corporate culture management of an enterprise[7]. All the above researches are limited in the level of the basic properties and structural elements of corporate culture to evaluate enterprise culture. However, enterprise culture management is a dynamic, continuous improvement process of systems engineering, and the above study did not realize the system evaluation on the enterprise culture management process. Aimed at the shortcomings of the above research, this paper from the perspective of enterprise culture management process, constructs the evaluation index system of the whole process of enterprise culture management, and put forward a comprehensive evaluation method based on entropy method and fuzzy comprehensive evaluation method.

\section{THE EVALUATION INDEX SYSTEM BASED ON PDCA}

Enterprise culture management starts from the formation and perfection of the Enterprise culture system, and tends to the realization of enterprise culture management, which runs through the whole process of enterprise development. Enterprise culture management develops with the development of the enterprise, thus the process of enterprise culture management should be a continuous improvement cycle. The PDCA cycle theory is the specific application of this idea. PDCA cycle is the basic method adopted by comprehensive quality management and has been widely used in enterprise management[8]. PDCA represents four stages of management: P-Plan, D-Do, C-Check and A-Action. According to the connotation of the PDCA cycle theory, the enterprise culture management process is decomposed into culture status diagnosis, culture fixed design, culture operation, culture assessment and culture improvement, and then the PDCA model of enterprise culture management process is built (Fig. 1).

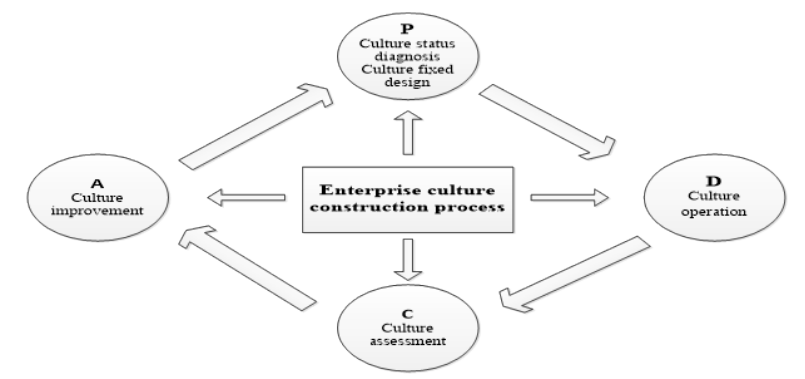

Fig. 1. The enterprise culture management process based on PDCA theory 
Based on the PDCA model of enterprise culture management process, the logical step of enterprise culture management process and the main work of each step are analyzed and obtained. By analyzing the characteristics of each sub-process, the evaluation index system of enterprise culture management is constructed (Fig. 2).

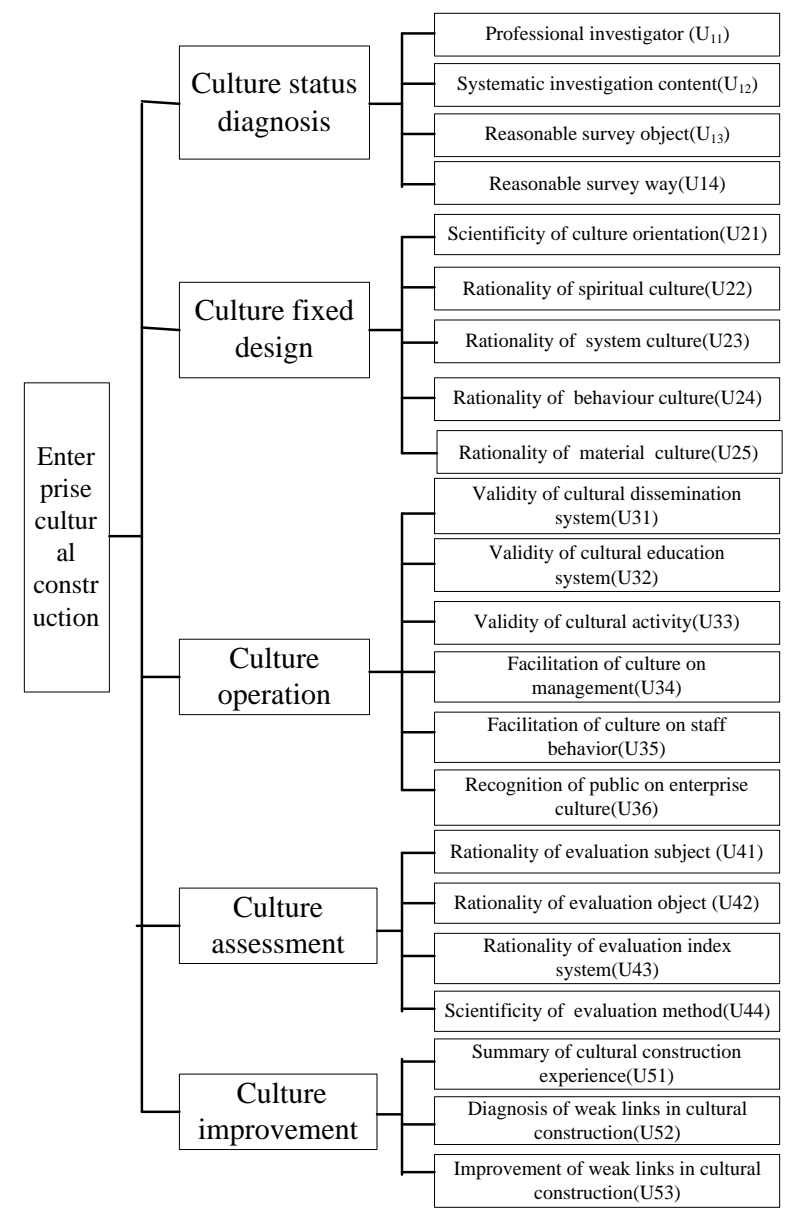

Fig. 2. The evaluation index system based on the whole process of enterprise culture management

\section{THE EVALUATION METHOD FOR ENTERPRISE CULTURE MANAGEMENT}

The evaluation of enterprise culture management is a complex system engineering, which involves knowledge of cognitive psychology, organizational behavior and other aspects. In addition, when evaluating the process of enterprise culture management, the evaluation subjects often use the ambiguous and the fuzzy word, thus the fuzzy comprehensive evaluation methods are extensively adopted. Meanwhile, the traditional enterprise culture evaluation methods always rely on the organizers and the expert's subjective judgment to determine the weight of each index[9]. Due to the quite different of personal experiences and knowledge, it makes different individuals giving quite different weights for the same evaluation indexes with the subjective color, which caused the evaluation results with larger distortion and even decisionmaking errors. Therefore, in this study, an improved entropy weight method was used to determine the weight of evaluation indexes, and the fuzzy comprehensive evaluation method was used to evaluate the enterprise culture management.

The concept of entropy is derived from thermodynamics, which is introduced by Shannon. According to the definition and principle of entropy, entropy can be used as a measure of the effective information in system. Entropy weight method is a quantitative evaluation method, which belongs to objective weighting method[10]. For an evaluation problem, suppose there are ${ }^{m}$ evaluation objects and $n$ evaluation indexes, the original evaluation matrix can be denoted as $X=\left(x_{i j}\right)_{m \times n}$, where $x_{i j}$ denotes the score of the ${ }^{i}$ th evaluation object on the ${ }^{j}$ th evaluation index.

Firstly, transform the matrix $X$ to the dimensionless form, the matrix $\mathrm{Y}=\left(y_{i j}\right)_{m \times n}$ is obtained.

$$
y_{i j}=\frac{x_{i j}}{\left[\sum_{i=1}^{m} x_{i j}^{2}\right]^{\frac{1}{2}}}
$$

Then, calculate the proportion of the score of the $i$ th evaluation object on the $j$ th evaluation index, that is $p_{i j}$.

$$
p_{i j}=\frac{y_{i j}}{\sum_{i=1}^{m} y_{i j}}
$$

Thirdly, the entropy value $h_{j}$ of $j$ th evaluation index can be obtained by the following formula:

$$
h_{j}=-\frac{1}{\ln m} \sum_{i=1}^{m} p_{i j} \ln p_{i j}, \quad(j=1,2,3 \ldots, n)
$$

According to the definition and principle of entropy, the greater the entropy value of an index is, the less effective information the index provides, the less important the function of the index in the comprehensive evaluation, the smaller the weight is; On the contrary, the greater the entropy value is, the more effective information the index provides, and the more important the function of the index in the comprehensive evaluation, the greater the weight is.

Furthermore, calculate the diversity factor $g_{j}$ of the $j$ th evaluation index.

$$
g_{j}=1-h_{j}
$$

For the $j$ th evaluation index, the greater $g_{j}$ is, the more important the index is for the evaluation. Otherwise, the smaller $g_{j}$ is, the less important the index is for the evaluation.

Based on the diversity factor $g_{j}$, the weight $w_{j}$ of the $j$ th evaluation index can be obtained:

$$
w_{j}=\frac{g_{j}}{\sum_{j=1}^{n} g_{j}}
$$

The formula $\mathrm{R}=W \cdot M$ is used to obtain the fuzzy evaluation matrix, and then we can obtain the relative degree of membership of the enterprise culture management process. However, according to the maximum membership degree 
principle, it can't exactly reflect the evaluation grades of object, and can't easily to compare the enterprise culture management process with other firms[11-12]. Therefore, the weighted average fuzzy operator $M(\square++)$ is used to carry out the comprehensive calculation, and the formula $S=\mathrm{R} \square V^{T}$ is used to calculate the evaluation score and level of the specific process of the enterprise culture management. In this way, it takes into account the integrality of the enterprise culture management process and the important role of all related factors.

\section{CASE STUDY}

For the project of promoting enterprise culture management in subordinate power supply company of Sichuan electric power company, the proposed enterprise culture management evaluation system is used to comprehensively evaluate the enterprise culture management level of the 3 power supply companies (Company A, B and C).

\section{A. Determining the index weight}

The backbones of power system enterprise culture and enterprise culture experts are organized to form an expert panel. For the evaluation index system proposed in this paper, the expert panel give the score from 1-5, and the higher score indicates that a company has higher enterprise culture management level on an index. The evaluation results of the experts are obtained (Table 1).

TABLE I. THE ORIGINAL DATA OF EXPERT ASSESSMENT

\begin{tabular}{lcccccccccccccccccccccccccc}
\hline & $U_{11}$ & $U_{12}$ & $U_{13}$ & $U_{14}$ & $U_{21}$ & $U_{22}$ & $U_{23}$ & $U_{24}$ & $U_{25}$ & $U_{31}$ & $U_{32}$ & $U_{33}$ & $U_{34}$ & $U_{35}$ & $U_{36}$ & $U_{41}$ & $U_{42}$ & $U_{43}$ & $U_{44}$ & $U_{51}$ & $U_{52}$ & $U_{53}$ \\
\hline $\mathrm{A}$ & 3 & 3 & 4 & 2 & 3 & 4 & 3 & 2 & 4 & 3 & 3 & 2 & 3 & 4 & 3 & 2 & 2 & 2 & 3 & 3 & 3 & 2 \\
\hline $\mathrm{C}$ & 5 & 4 & 3 & 3 & 3 & 3 & 4 & 3 & 3 & 4 & 2 & 2 & 3 & 2 & 3 & 1 & 2 & 1 & 2 & 2 & 3 & 2 \\
\hline $\mathrm{D}$ & 3 & 4 & 3 & 3 & 4 & 3 & 4 & 3 & 3 & 3 & 3 & 3 & 2 & 3 & 3 & 3 & 2 & 2 & 3 & 3 & 4 & 3 \\
\hline
\end{tabular}

Because the expert assessment scores are dimensionless According to the formula (2), calculate $p_{i j}$ (Table. 2).

data, so there is no need for dimensionless processing.

TABLE II. THE PROPORTION OF THE SCORE OF THE $i$ TH EVALUATION OBJECT ON THE $j$ TH EVALUATION INDEX

\begin{tabular}{ccccccccccccccccc}
\hline & $U_{11}$ & $U_{12}$ & $U_{13}$ & $U_{14}$ & $U_{21}$ & $U_{22}$ & $U_{23}$ & $U_{24}$ & $\ldots \ldots$ & $U_{41}$ & $U_{42}$ & $U_{43}$ & $U_{44}$ & $U_{51}$ & $U_{52}$ & $U_{53}$ \\
\hline $\mathrm{A}$ & 0.27 & 0.30 & 0.30 & 0.26 & 0.30 & 0.40 & 0.28 & 0.26 & $\ldots \ldots$ & 0.33 & 0.33 & 0.40 & 0.37 & 0.37 & 0.30 & 0.28 \\
\hline $\mathrm{C}$ & 0.46 & 0.40 & 0.23 & 0.37 & 0.30 & 0.30 & 0.36 & 0.37 & $\ldots \ldots$ & 0.17 & 0.33 & 0.20 & 0.26 & 0.26 & 0.30 & 0.28 \\
\hline $\mathrm{D}$ & 0.27 & 0.40 & 0.23 & 0.37 & 0.40 & 0.30 & 0.36 & 0.37 & $\ldots \ldots$ & 0.50 & 0.33 & 0.40 & 0.37 & 0.37 & 0.40 & 0.44 \\
\hline
\end{tabular}

According to the formula (3)-(5), the entropy value, diversity factor and weight of each index can be obtained and shown in the table 3 .

TABLE III. THE ENTROPY VALUE, DIVERSITY FACTOR AND WEIGHT OF EACH INDEX

\begin{tabular}{|c|c|c|c|c|c|c|c|c|c|c|c|c|c|c|c|c|}
\hline & $U_{11}$ & $U_{12}$ & $U_{13}$ & $U_{14}$ & $U_{21}$ & $U_{22}$ & $U_{23}$ & $U_{24}$ & $\ldots \ldots$ & $U_{41}$ & $U_{42}$ & $U_{43}$ & $U_{44}$ & $U_{51}$ & $U_{52}$ & $U_{53}$ \\
\hline$h_{j}$ & 0.97 & 0.992 & 0.994 & 0.99 & 0.994 & 0.995 & 0.98 & 0.994 & ...... & 0.953 & 0.98 & 0.98 & 0.99 & 0.98 & 0.994 & 0.985 \\
\hline$g_{j}$ & 0.02 & 0.008 & 0.006 & 0.01 & 0.006 & 0.005 & 0.02 & 0.006 & $\ldots \ldots$ & 0.047 & 0.02 & 0.02 & 0.01 & 0.02 & 0.006 & 0.015 \\
\hline$w_{j}$ & 0.05 & 0.03 & 0.02 & 0.04 & 0.02 & 0.02 & 0.055 & 0.02 & $\ldots \ldots$ & 0.128 & 0.055 & 0.055 & 0.027 & 0.055 & 0.02 & 0.041 \\
\hline 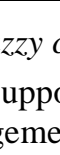 & 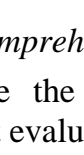 & $i$ & & & & & & & $\begin{array}{l}U_{3} \\
U_{4} \\
U_{5}\end{array}$ & $\begin{array}{l}=\left(U_{31}\right. \\
=\left(U_{41}\right)\end{array}$ & $\begin{array}{l}U_{32}, L \\
U_{42}, L\end{array}$ & $\begin{array}{l}{ }_{33}, U_{34}, L \\
{ }_{13}, U_{44}, L\end{array}$ & $\begin{array}{l}U_{35}, U_{36} \\
\left.U_{45}\right)\end{array}$ & & & \\
\hline
\end{tabular}

$U=\left(U_{1}, U_{2}, U_{3}, U_{4}, U_{5}\right)$.

The second index set are

$U_{1}=\left(U_{11}, U_{12}, U_{13}, U_{14}, U_{15}\right)$

$U_{2}=\left(U_{21}, U_{22}, U_{23}, U_{24}, U_{25}, U_{26}\right)$
Moreover, set the score range as 1-4, and build the judge set $\quad V=\{$ Excellent(4),Good(3), Qualified(2),Unqualified(1) $\}$. Based on the judgement data, the fuzzy evaluating matrixes of four firms are 


$$
\begin{gathered}
R_{A}=\{0.345,0.273,0.225,0.157\} \\
R_{B}=\{0.298,0.322,0.279,0.101\} \\
R_{C}=\{0.126,0.237,0.244,0.393\} .
\end{gathered}
$$

Then, using the $S=\mathrm{R} V^{T}$ for synthetical calculation, and we get the $S_{A}=2.806, S_{B}=2.847$ and $S_{C}=2.096$. Therefore, the enterprise culture management level of A, B, C and D company are respectively, and $\mathrm{B}>\mathrm{A}>\mathrm{C}$. For the evaluation of the whole level of enterprise culture management, it helps to get a more objective and overall understanding about the enterprise culture management status by comprehensively consider the whole process of enterprise culture management. On this basis, a quantitative method for evaluation of enterprise culture management is proposed, which gets some achievements.

\section{CONCLUSION}

Enterprise culture management has become a research hot spot, but the quantitative evaluation of the process and effect of enterprise culture are rarely studied. From the perspective of whole life cycle of enterprise culture development, this paper defines the basic enterprise culture management process based on the PDCA cycle theory, and on this basis builds the evaluation index system of the whole process of enterprise culture management. To perform the evaluation of enterprise culture management, the entropy method is used to determine the weight of evaluation index of enterprise culture management, which avoids the subjectivity of traditional expert evaluation method and other subjective methods to determine index weight, and makes the evaluation results more objective and accurate. Furthermore, the fuzzy comprehensive evaluation method is applied to improve the rationality of the evaluation results. Actual application shows that the proposed evaluation system has the feasibility and effectiveness, which provides a more comprehensive reference for further improvement and perfection of enterprise culture management. At the same time, this study plays a leading role for the future enterprise culture management for the, and it is conducive to making a more perfect and objective plan for the enterprise culture management.

\section{ACKNOWLEDGMENT}

This work is supported by the National Science Foundation of China (71701027).

\section{REFERENCES}

[1] Ai-Zhen M I. Construct Excellent Enterprise Culture and Promote Core Competence. Modern Industrial Economy \& Informationization, 2012.

[2] Xiong Y, Xie B, Chang W, et al. The Research on Evaluation System of Culture for Information Enterprises. Science of Science \& Management of S \& T, 2008, 29(1):144-148.

[3] Hofstede G, Neuijen B, Ohayv D D, et al. Measuring Organizational Cultures: A Qualitative and Quantitative Study Across Twenty Cases. Administrative Science Quarterly, 1990, 35(2):286-316.

[4] Deshpande, R., J. U.Farley. Organizational Culture, Market Orientation, Innovativeness and Firm Performance: an International Research Odyssey. Internal Journal of Research in Marketing, 2004(21):3-22

[5] Tian J, Zhang G, Jiang W. A Study on the Validity and Reliability of Denison OCQ and Its Application. Science of Science \& Management of S \& T, 2008, 29(2):151-156.

[6] Fu J. Application of FAHP in Comprehensive Evaluation of Enterprise Culture. Journal of Wuhan University of Technology, 2007(3): 152-155.

[7] Yongyou W, Xisong L, Yuhe D. Establishment of an evaluation model for corporate culture management. Journal of Harbin Engineering University, 2004, 25(6): 822-827.

[8] Kanji G K. Total quality management: the second industrial revolution. Total Quality Management, 1990, 1(1): 3-12.

[9] Pang Y, Liu K, Zhang B. The Method of Determining the Objective Index Weight in the Synthetic Evaluation System. Systems Engineeringtheory \& Practice, 2001(8):37-42.

[10] Zhang X. Research on the supplier selection of a supply chain based on entropy weight and improved ELECTRE-III method. International Journal of Production Research, 2011, 49(3):637-646.

[11] Mosleh M. Evaluation of fully fuzzy matrix equations by fuzzy neural network. Applied Mathematical Modeling, 2013, 37(9):6364-6376.

[12] Bing W, Wang S L, Li L. Fuzzy comprehensive evaluation of district heating systems. Energy Policy, 2010, 38(10):5947-5955. 